\title{
Cenários para o Setor Turístico no Estado do Ceará (Brasil) para o período de 2013 a 2023
}

\section{Scenario for the Tourism Sector in Ceará State (Brazil) for the period from 2013 to 2023}

\author{
Camilla Cruz de Carvalho (CARVALHO, C. D. de)
}

Joyce da Silva Albuquerque (ALBUQUERQUE, J. da S.) ${ }^{* *}$

\author{
Raissa Karen Leitinho Sales (SALES, R. K. L.)
}

Márcia Lopes Cardoso (CARDOSO, M. L.) ${ }^{* * * *}$

Rosângela Queiroz Souza Valdevino (VALDEVINO, R. Q. S.)

Sérgio Henrique Arruda Cavalcante Forte (FORTE, S. H. A. C.)

RESUMO - Esta pesquisa tem como objetivo geral elaborar cenários mais prováveis
para o turismo no estado do Ceará (Brasil), considerando o período de 2013 a 2023, e
tem como objetivo específico propor estratégias públicas e privadas para os cenários

\begin{abstract}
* Formação: Graduação em Administração de Empresas pela Universidade de Fortaleza (Unifor), Mestranda em Administração de Empresas na Unifor. Endereço físico para correspondência: Avenida Rogaciano Leite, 250, ap. 2402 B. CEP: 60810-001 - Fortaleza - Ceará (Brasil). Telefone: +55(85) 9665.2850. E-mail: camillacruzc@ hotmail.com

** Formação: Graduação em Administração de Empresas com Habilitação em Marketing pela Faculdade Piauiense, Especialização em Metodologia do Ensino Superior (INTA), Mestranda do Programa de PósGraduação em Administração de Empresas da Unifor. Atividade profissional: Professora da Universidade Estadual Vale do Acaraú. Endereço físico para correspondência: Avenida Historiador Raimundo Girão, 630, Praia de Iracema. CEP: 60165-050 - Fortaleza - Ceará (Brasil). Tel: +55 (85) 9627.4021. E-mail: joycea_20@hotmail.com

Formação: Graduação em Comunicação Social (Unifor), Especialização em Assessoria de Comunicação (Unifor), Mestrado pelo Programa de Pós-Graduação em Administração de Empresas da Unifor. Endereço físico para correspondência: Rua Desembargador Carvalho Lima, 177, Jardim das Oliveiras. CEP: 60821-120 - Fortaleza - Ceará (Brasil). Telefone: +55 (85) 8803.5121. E-mail: raikaren@hotmail.com
\end{abstract}

**** Formação: Graduação em Administração de Empresas pela Faculdade Leão Sampaio (FALS), Mestrado pelo Programa de Pós-Graduação em Administração de Empresas da Unifor, Master in Strategic and International Management (Dupla Titulação) Technische Hochschule Deggendorf THD (Alemanha). Endereço físico para correspondência: Avenida Humberto Monte, 1799, ap. 203, Bloco D, Parquelândia. CEP: 60450-000 - Fortaleza - Ceará (Brasil). Telefones: (85) 3287-2497 / (85) 99145499. E-mail: marciacardoso87@hotmail.com

Formação: Graduação em Ciências Contábeis e Especialização em Auditoria Contábil pela Universidade do Estado do Rio Grande do Norte (UERN), Mestrado pelo Programa de Pós-Graduação em Administração de Empresas da Unifor. Atividade profissional: Professora da Universidade do Estado do Rio Grande do Norte (UERN). Endereço físico para correspondência: Rua Jacinto de Oliveira, 43. CEP: 597000-000 - Apodi - Rio Grande do Norte (Brasil). E-mail: rosangelaqueiroz84@yahoo.com

Formação: Graduação em Engenharia Civil pela Universidade Federal do Ceará (UFC) e em Administração de Empresas pela Universidade Estadual do Ceará (UECE), Mestrado e Doutorado em Administração de Empresas pela Fundação Getúlio Vargas (FGV-EAESP). Atividade profissional: Professor titular da Unifor. Endereço físico para correspondência: Avenida Paisagística, 100, ap. 804, Bloco 3. CEP: 608125-35 - Fortaleza - Ceará (Brasil). Telefone para contato: +55 (85) 8605.0078. Email: sergioforte@unifor.br 
prospectados. A metodologia utilizada é de cunho descritivo, qualitativo, utilizando-se de material secundário, além de consulta a expertises e apoio da matriz MICMAC. O resultado do trabalho foi a elaboração de dois cenários, um realista e outro pessimista, com a proposição de políticas públicas para cada um deles. O cenário realista projeta que o mix de serviços oferecidos pelas empresas e o Estado será ampliado, no que se refere a atrações turísticas cearenses. Para o cenário pessimista, considera-se que haverá um encolhimento do investimento em atrações turísticas no Ceará, com redução do mix dos serviços oferecidos pelas empresas e menor valorização da capacitação da mão de obra local.

Palavras chave: Cenários Prospectivos; Turismo; Política Pública.

ABSTRACT - This research aims at exploring the most likely scenarios for tourism in the state of Ceará (Brazil) considering the period from 2013 to 2023. As specific goal it proposes public and private strategies for prospected scenarios. The research methodology used is descriptive and qualitative. The process of data collection was conducted through interviews with experts, secondary data and it was supported by application MICMAC matrix. The result of this work was the development of two scenarios, one realistic and the other pessimistic, proposing public policies for each one of them. The realistic scenario proposes that the mix of services offered by companies and the public sector will be expanded considering tourist attractions in Ceará. For the pessimist scene, it is considered occurring shrinkage in investment in tourist attractions in Ceará, and will reduce the mix of services provided by companies and the local labor will be less valued.

Key words: Prospective Scenario; Tourism; Public Policy. 


\section{INTRODUÇÃO}

O turismo é considerado o maior dos movimentos migratórios da história da humanidade (CUNHA, 2010).

Nessa perspectiva, em um estudo acerca da disseminação da prática turística no território nacional, Tomazzoni (2007, p. 83) compreende que "[...] têm aumentado, no Brasil, a difusão e a assimilação do conceito do turismo como um dos setores com menor exigência de investimentos e maiores garantias de retorno ou lucros".

No estudo sobre o impacto econômico mundial do turismo, desenvolvido e divulgado pelo World Travel \& Tourism Council - WTTC (2012), constatou-se que, somente no ano de 2011, o setor de turismo movimentou US\$ 6,3 trilhões, algo em torno de 9,1\% do Produto Interno Bruto - PIB mundial. No mesmo ano, a atividade turística contribuiu para a geração de empregos diretos e indiretos, tendo sido responsável por mais de 255 milhões de postos de trabalhos, o equivalente a 8,7\% dos empregos do mundo (WTTC, 2012).

No Brasil, no $4^{\circ}$ trimestre de 2012, as empresas do setor de turismo apresentaram comparativamente ao mesmo período de 2011 uma variação positiva média de faturamento de 5,6\% (MTUR, 2013a). Dentre os mais importantes fatores favoráveis a tal crescimento, destacam-se os investimentos realizados pelas empresas e a maior divulgação dos atrativos e roteiros turísticos.

A atração de visitantes provocada pela realização de grandes eventos esportivos no país, tais como a Copa das Confederações, em 2013, a Copa do Mundo de Futebol da Fédération Internationale de Football Association - FIFA, em 2014, e os Jogos Olímpicos de 2016, bem como a própria estabilização econômica brasileira, são fatores que favorecem um cenário para projetar a evolução do turismo para a próxima década, de acordo com o Conselho de Turismo e Negócios (CTNF) da Federação de Comércio de Bens, Serviços e Turismo - Fecomércio (CTNF, 2011).

A movimentação dos aeroportos brasileiros no ano de 2012, de acordo com o Boletim de Desempenho Econômico do Turismo (2012), foi a maior dos últimos 14 anos. No período de um ano, os desembarques domésticos totalizaram 84.863.693, superando em 7,1\% os 79.244.256 computados em 2011 (MTUR, 2013b). Quanto aos voos internacionais, houve um crescimento de 2,4\% em relação a 2011. Além disso, os 
dados da Infraero apontam que ocorreram 9.236.947 desembarques estrangeiros no Brasil no ano de 2012 (MTUR, 2013c).

Segundo Portuguez (2002), os resultados do movimento financeiro decorrentes do turismo são expressivos e justificam a preocupação de governos e entidades na busca pelo seu fortalecimento. Nessa perspectiva, o estudo de cenários prospectivos torna-se um instrumento relevante para a expansão do turismo, ao passo que contribui por meio de debates sobre as relações futuras das organizações e de uma projeção de estratégia competitiva para o setor, oportunizando embasamento para tomadores de decisões e minimização de riscos (GODET, 2000; MARCIAL; GRUMBACH, 2002; PORTER, 1990).

Para que uma região ou localidade se torne um destino turístico nacional e internacional, são exigidos fatores locais, como também ações estratégicas e de infraestrutura dos poderes públicos federal, estaduais e de instituições relacionadas (CRUZ, 2006).

Diante do exposto, este estudo tem como problema de pesquisa a seguinte indagação central: quais estratégias as instituições governamentais e os empresários deveriam considerar para prospecção do setor turístico cearense nos cenários mais prováveis dos próximos dez anos? O objetivo geral da pesquisa consistiu na elaboração de cenários mais prováveis para o turismo cearense nos próximos dez anos (2013 2023). Dessa forma, teve-se como objetivo específico sugerir estratégias públicas e privadas para os cenários mais prováveis encontrados.

A relevância da pesquisa é confirmada pelo fato de o Ceará ser um dos estados mais visitados no Brasil, conforme dados da Secretaria de Turismo do Estado do Ceará (Setur), constituindo-se também uma das principais atividades econômicas desenvolvidas no Estado (SETUR, 2013).

Acredita-se, portanto, que a identificação de cenários prospectivos no que se refere à atividade turística no Ceará poderá auxiliar no processo de planejamento e ações por parte dos setores público e privado para os próximos anos, para implementação de políticas, melhorias de estrutura e acesso, investimentos em ações educativas e ambientais, dentre outras iniciativas para a progressão do turismo no Ceará, bem como no restante do País. 


\section{CENÁRIOS PROSPECTIVOS}

A origem da proposição de cenários ocorreu com o objetivo de eliminar ou pelo menos reduzir as incertezas sobre determinados ambientes que sofrem instabilidades. Para Marcial e Grumbach (2002), os cenários possibilitam debates sobre as relações futuras das organizações, em que os tomadores de decisões possam agir com maior precisão e fundamentação. Para Porter (1990), a compreensão dos possíveis cenários futuros apoia a implantação de uma estratégia competitiva.

Para Heijden (2009), cenários constituem um conjunto de futuros razoavelmente plausíveis, mas estruturalmente diferentes e concebidos por um método de reflexão mais causal do que probabilístico para a formulação de estratégias de atuação nos modelos de futuros.

O modelo proposto por Godet (2003), denominado de método de elaboração de cenário prospectivo, utilizado nesse trabalho, propõe uma análise estruturada, utilizando ferramentas que auxiliam a obter condições de relevância, coerência, plausibilidade e transparência.

Para a construção de cenários, a literatura dispõe de algumas ferramentas e metodologias que podem auxiliar nas suas elaborações, tais como as encontradas em Brainstorming (2003); Day e Schoemaker (2005); Godet (2000; 2003) e Porter (1990).

Os estudos acadêmicos no setor do turismo empregando metodologias de cenários não são tão abundantes. No campo internacional, listam-se alguns dos principais estudos: Gössling e Scott (2012), Hunt et al. (2005), Moriarty (2012), Shuifa et al. (2011) e, no Brasil, mesmo sendo um país propício ao turismo, há poucos trabalhos publicados na academia: Alves et al. (2009), Costa et al. (2006), Costa e Nascimento (2007), Sobreira et al. (2013) e Valença et al. (2010).

O uso da ferramenta de cenários prospectivos pode auxiliar o processo estratégico das organizações, uma vez que tem como objetivo estudar as diversas possibilidades de futuros existentes e preparar as organizações para enfrentá-las, ou até mesmo criar condições para que modifiquem as probabilidades de ocorrência de situações incertas, ou minimizar seus efeitos (COSTA et al., 2006; GODET, 2003). 


\subsection{SITUAÇÃO ATUAL DO TURISMO NO ESTADO DO CEARÁ}

O estado do Ceará tem se destacado como um dos destinos mais procurados para o turismo. De acordo com dados da Setur (2013a), no ano de 2011, o Ceará recebeu 2,8 milhões de turistas via Fortaleza. Os meses de janeiro, julho e dezembro são historicamente os que mais recebem visitantes no estado. Para o ano de 2011, esses meses juntos corresponderam a aproximadamente $34 \%$ do total de turistas e $92,27 \%$ das pessoas que visitaram o Ceará eram provenientes do turismo interno brasileiro. Já em 2012, o Ceará recebeu em média 2,9 milhões, ou 3,6\% a mais do previsto para 2011 (SETUR, 2013a).

O Estado acolherá entre os anos de 2013 e 2016 importantes eventos esportivos que fomentarão ainda mais o turismo na região. Fortaleza, a capital cearense, foi uma das cidades-sede da última Copa das Confederações e será da Copa do Mundo de Futebol da FIFA 2014.

Segundo estimativa do Ministério do Turismo (2014) acerca da entrada de turistas brasileiros e estrangeiros durante o Mundial, a capital cearense está entre as principais cidades-sede, com um número de 402 mil visitantes no período. Em Fortaleza, serão disputados nove jogos entre a Copa das Confederações e a Copa do Mundo. O estádio que recebe esse tipo de competição tem capacidade para $60.342 \mathrm{mil}$ pessoas, sendo a maior arena brasileira das regiões Norte e Nordeste (FIFA, 2014a, 2014b).

Outros acontecimentos esportivos, culturais, empresariais e políticos podem ser considerados, como seminários e congressos nos centros de eventos do Estado e também comemorações tradicionais, como as festas religiosas, o réveillon e o carnaval realizados em arenas, centros culturais e outras estruturas públicas dos interiores e na capital cearense.

\section{METODOLOGIA}

A pesquisa realizada pode ser classificada como sendo qualitativa e descritiva, utilizando a análise exploratória de dados e a estatística descritiva. Por meio da 
observação indireta e de técnicas descritivas, buscou-se explicitar os fatos observados, registrar, analisar e correlacionar as variáveis (CERVO; BERVIAN; SILVA, 2007; FLICK, 2004).

Ressalta-se a necessidade de se realizar um estudo aprofundado do ambiente que está sendo investigado, levando à compreensão de processos que estão em fase de concretização, possibilitando a antecipação do futuro (BUARQUE, 2003).

A busca por fontes secundárias de dados se realizou por meio de um levantamento aprofundado sobre o tema em livros, periódicos científicos, revistas, jornais e internet, além da coleta dos dados primários nas pesquisas de campo.

Para a construção de cenários prospectivos, propostos nesta pesquisa, seguiu-se como linha-base o modelo abordado por Godet (2000), tomando como exemplo o modelo adaptado demonstrado nos métodos de pesquisa de Oliveira e Forte (2009).

Para atingir os objetivos da pesquisa, a metodologia foi composta pelas seguintes etapas:

\subsection{RECENSEAMENTO DAS VARIÁVEIS}

Por meio da pesquisa secundária, foram listadas inicialmente 35 variáveis determinantes, de acordo com as observações acerca do tema e das inclinações relevantes sobre o contexto em estudo, como também a definição de seus atores.

Considerando as variáveis elencadas, estruturou-se um questionário, mantendo a clareza ao explicar a relevância do tema e do estudo e as contribuições acadêmicas e gerenciais decorrentes, considerando como questionamento central a influência das variáveis no setor turístico cearense em um futuro de dez anos.

Adicionalmente, foi realizada uma aplicação com 25 estudantes, entre mestrandos e doutorandos, e com o professor da disciplina de Cenários Estratégicos do Programa de Pós-Graduação em Administração de uma universidade, com o intuito de realizar um aprimoramento das variáveis elencadas pela literatura e validar o instrumento de pesquisa.

Após a aplicação do pré-teste, mantiveram-se no questionário as 35 variáveis, para avaliação dos especialistas sobre o tema turismo no estado do Ceará. 


\subsection{APLICAÇÃO DO INSTRUMENTO DE PESQUISA AOS ESPECIALISTAS}

Nesta fase, utilizou-se a orientação de Godet (2000), que preconiza o dimensionamento de 10 a 20 respondentes para auxiliar no recenseamento das variáveis. Assim, dez questionários foram encaminhados a especialistas do setor turístico cearense. Foram considerados como especialistas professores e coordenadores de cursos de turismo; gestores de hotéis; e proprietários de agências de turismo.

Os dez questionários coletados tiveram como objetivo selecionar as variáveis que os especialistas consideravam de maior relevância, utilizando-se da escala Likert de 0 a 3 pontos, da menor influência para a maior influência (MALHOTRA, 2006), considerando os seguintes níveis: nenhuma influência; fraca influência; moderada influência; e forte influência.

\subsection{TRATAMENTO DAS VARIÁVEIS}

Após a coleta dos dez questionários aplicados aos especialistas, tomando como exemplo o método demonstrado no trabalho de Sobreira et al. (2013) sobre cenários prospectivos no combate ao turismo sexual internacional em Fortaleza, elaborou-se um ranking da variável de maior peso para a de menor peso, por meio da média dos resultados e utilizando-se o software Microsoft Excel 2010, para poder definir quais as variáveis que comporiam os cenários de turismo no Ceará nos próximos dez anos, da variável mais influente para a menos influente.

Para encontrar as variáveis-chave, fez-se necessário realizar um corte nesse ranking, com o intuito de reduzir ao máximo o número de variáveis. As variáveis foram tratadas de acordo com a metodologia proposta por Oliveira e Forte (2009), os quais ressaltam que as variáveis que devem permanecer são somente aquelas consideradas mais importantes e que possuem maior influência na definição dos cenários futuros, segundo a visão dos especialistas.

Como critério de corte, utilizou-se média ponderada e desvio-padrão das notas das variáveis, possibilitando a aplicação da distribuição normal, adotando-se como valores de corte as variáveis cujas médias estivessem abaixo de 2,7102; valor obtido pelo somatório da média das médias com a soma de três desvios-padrão. Assim, treze 
variáveis foram excluídas, ficando 22 variáveis que obtiveram média igual ou superior a 2,7102 .

\subsection{RECENSEAMENTO DAS VARIÁVEIS-CHAVE (2 $2^{\mathrm{a}}$ RODADA)}

Com o objetivo de reduzir ainda mais o número de variáveis para a realização da próxima etapa, utilizou-se o método Delphi, considerando que ele tem por objetivo a efetiva utilização do julgamento intuitivo, permitindo a utilização de etapas de checagem de um painel de especialistas repetidas vezes, até se alcançar o consenso interdisciplinar e correspondente à redução do viés individual; idiossincrasias e situações de respostas que evidenciem ignorância sobre um determinado tema (CLIBBENS; WALTERS; BAIRD, 2012). No caso desta pesquisa, realizou-se uma variação na utilização do método Delphi original, pois este trabalho só cumpre apenas três dos principais passos do método: consulta a especialistas; categorização dos dados; e retorno aos especialistas em busca de um maior consenso, não seguindo, portanto, todas as etapas do método original (CLIBBENS; WALTERS; BAIRD, 2012; THOMPSON, 2009).

Assim, foram encaminhados novos questionários aos dez especialistas da fase anterior, contendo as 22 variáveis, com um convite para a participação de um grupo focal. Como não houve condições para a participação de um grupo focal, posto que não houve acordo entre os horários e datas disponíveis pelos participantes, a coleta se deu via resposta por email.

A resposta individual pode minimizar a interferência e a influência entre os participantes em um grupo focal (LINSTONE; TUROFF, 2002).

Para o segundo tratamento estatístico, elaborou-se uma nova medida de corte, tendo como valor de corte as variáveis cujas médias estivessem abaixo de 2,5487; valor alcançado com o somatório da média das médias com o desvio-padrão, permanecendo após o corte 10 variáveis, quantidade considerada coerente para ser utilizada na fase seguinte da pesquisa.

No quadro 1 se expõe as 10 variáveis que restaram e suas codificações, que foram aplicadas na Matriz de Influência Direta, no software MICMAC: 
QUADRO 1- VARIÁVEIS APLICADAS NO MICMAC

\begin{tabular}{|c|l|l|}
\hline No $^{\mathbf{0}}$ & \multicolumn{1}{|c|}{ VARIÁVEIS APLICADAS NO MICMAC } & \multicolumn{1}{|c|}{$\begin{array}{c}\text { LEGENDA } \\
\text { MICMAC }\end{array}$} \\
\hline 1 & Desempenho da economia brasileira & DESEMCOB \\
\hline 2 & Rotas /preços das passagens nacionais /internacionais & ROPREPNINT \\
\hline 3 & $\begin{array}{l}\text { Divulgação do turismo cearense nas mídias nacionais e } \\
\text { internacionais }\end{array}$ & DIVULGMIN \\
\hline 4 & Segurança & SEGURANÇA \\
\hline 5 & Infraestrutura aeroportuária & INFRAERO \\
\hline 6 & Preços (hotel, alimentação, transporte, lazer) & PRECOSAHTL \\
\hline 7 & Mix de serviços oferecidos pelas empresas locais & MIXSERV \\
\hline 8 & Atrações turísticas & ATRACTURIS \\
\hline 9 & $\begin{array}{l}\text { Capacitação de mão de obra (profissionais poliglotas, atendimento } \\
\text { personalizado, relacionamento com o cliente) }\end{array}$ & CAPMOD \\
\hline 10 & Crescimento da massa salarial no país & CRESCMASAL \\
\hline
\end{tabular}

Fonte: Dados da pesquisa (2013).

\subsection{APLICAÇÃO DA MATRIZ DE DUPLA ENTRADA}

Nesta etapa, sete especialistas, sendo seis dos 10 anteriores, e mais um excoordenador de Desenvolvimento Institucional do Programa de Desenvolvimento do Turismo no Nordeste (Prodetur) do Banco do Nordeste do Brasil preencheram um questionário de dupla entrada, em que cada variável foi confrontada com as demais, por meio de uma escala do tipo Likert de 0 a 3 pontos, sendo 0 (nenhuma influência); 1 (fraca influência); 2 (moderada influência); e 3 (forte influência) (MALHOTRA, 2006).

\subsection{RODADA NO MICMAC}

Após o preenchimento dos sete questionários, um único questionário foi produzido composto pelas médias aritméticas dos valores obtidos dos sete questionários, obedecendo ao critério de arredondamento para o número inteiro maior ou menor dependendo do caso, e excluindo-se as variáveis que tivessem coeficiente de variação (desvio-padrão/média) até 20\% (GODET, 2003), o que não foi o caso.

Em seguida, o questionário resultante foi aplicado na matriz de influência direta, por meio do aplicativo computacional MICMAC, desenvolvido por Godet (2003) no Laboratorie d'Investigation en Prospective Stratégie et Organisation (LIPSOR) e Conservatoire National des Arts e Métiers (CNAM). A matriz MICMAC de Godet (2000), no tratamento do grau de motricidade e dependência das variáveis, apresenta quatro quadrantes: de motricidade, de ligação, de resultado, e excluídas. Os resultados 
permitem gerar uma interpretação do comportamento futuro de determinada variável (GODET, 2000).

Em seguida, podem ser gerados cenários alternativos, considerando as variáveischave e estudos importantes sobre a temática, extraindo possíveis comportamentos e contextos futuros, conforme relatam Marcial e Costa (2002).

\subsection{CONSTRUÇÕES DOS CENÁRIOS E DAS ESTRATÉGIAS}

Os cenários foram construídos pela equipe de pesquisadores, com base nos resultados da matriz motricidade-dependência rodada na fase anterior, e ainda por meio de dados secundários para basear a redação dos dois textos, sendo um realista e outro pessimista (OLIVEIRA; FORTE, 2009). A construção dos dois cenários foi baseada na metodologia MORPHOL de Godet (2000), sem uso do aplicativo, procurando-se consolidar a ligação entre as variáveis, inserindo-as nos dois cenários. Esses dois cenários foram reapresentados aos seis especialistas.

\subsection{IDENTIFICAÇÃO DAS POLÍTICAS PÚBLICAS FRENTE AOS CENÁRIOS PROSPECTADOS POR PARTE DO GOVERNO FEDERAL}

Após a edição dos dois cenários, foram entrevistados os seis especialistas da fase anterior, para se coletar as estratégias de atuação nos dois cenários traçados. As entrevistas duraram em média 30 minutos. Dados secundários também foram utilizados para a consolidação das estratégias.

Toda a pesquisa foi realizada em um período de sete meses, de outubro de 2012 a maio de 2013.

\section{RESULTADOS}

Para a construção dos cenários, um realista e outro pessimista, utilizaram-se as ligações entre as variáveis-chave encontradas expostas no quadro 1, baseadas nos depoimentos colhidos com sete especialistas do setor de turismo durante as fases de 
aplicação dos questionários. A participação dos especialistas permitiu observar a relação de influência entre as variáveis, informações que foram, em seguida, cruzadas pelo software MICMAC.

Para a construção dos cenários, traçou-se uma linha transversal (gráfico 1) no mapa gerado pelo software MICMAC, dividindo o diagrama em duas partes, sendo aproveitadas para o estudo somente as variáveis acima da linha traçada por possuírem alta influência e alta dependência. De acordo com Godet (2000), as variáveis do Quadrante 4 (Q4) não são relevantes para os cenários que se pretendia descrever, devendo ser excluídas. Já o Quadrante 1 (Q1) trata das variáveis de entrada, aquelas que mais exercem influência nas demais variáveis, mas de pouca dependência; no Quadrante 2 (Q2), ficam as variáveis de ligação, que tanto exercem influência como são influenciadas; no Quadrante 3 (Q3), estão localizadas as variáveis mais dependentes e que exercem pouca influência nas demais; no Quadrante 4 (Q4), localizam-se as variáveis excluídas.

GRÁFICO 1 - MICMAC - DIAGRAMA DE INFLUÊNCIA (EIXO VERTICAL) X DEPENDÊNCIA (EIXO HORIZONTAL)

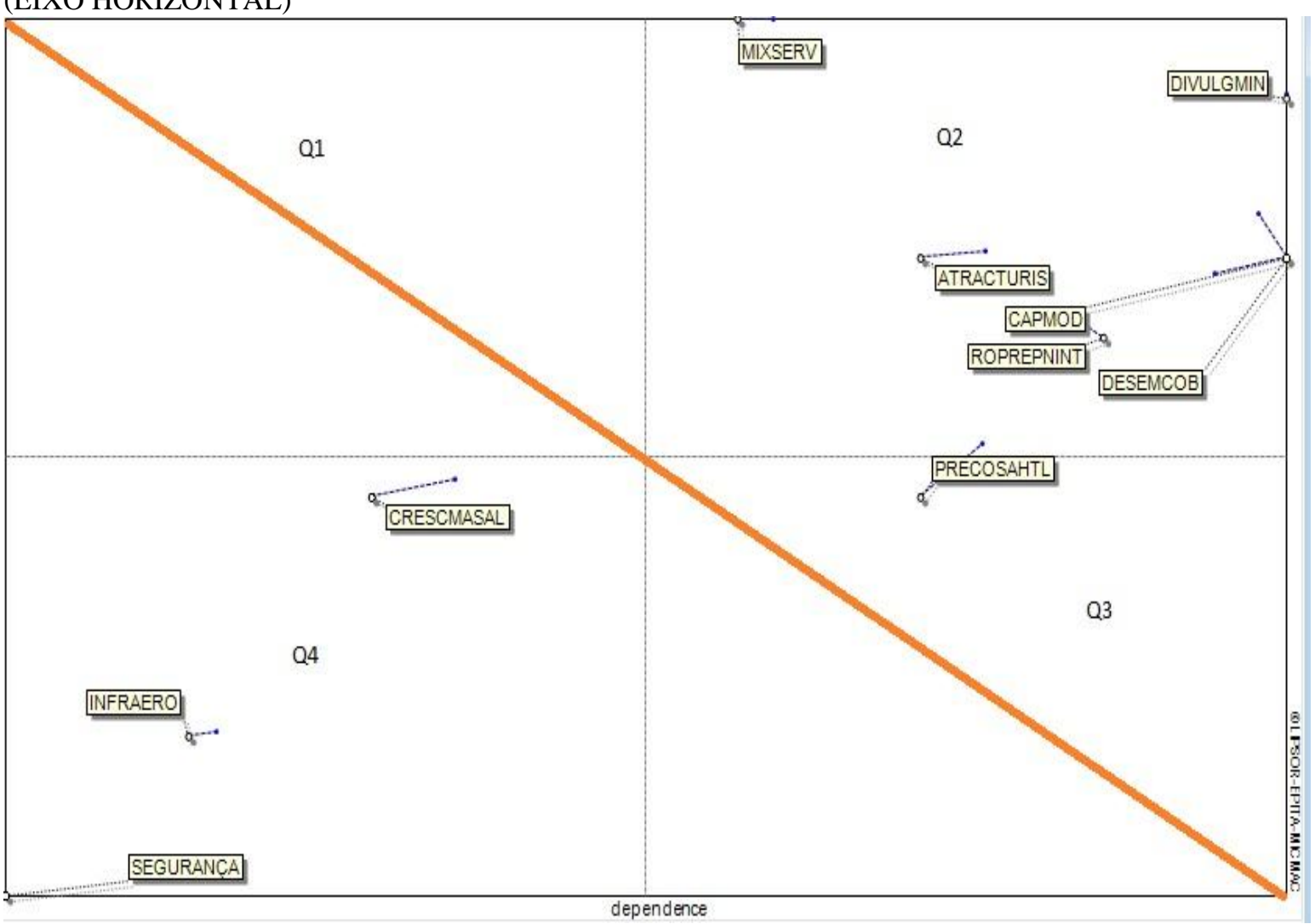

Fonte: Dados da pesquisa aplicados no MICMAC. 
Assim, as 10 variáveis aplicadas com os sete especialistas e com apoio do MICMAC geraram as variáveis localizadas no Q2 do gráfico, que representam uma forte influência. Portanto, trata-se de fatores representativos para desenvolver com ênfase a atividade turística. Os itens identificados no Q1 do gráfico seriam os que mais exercem influência nas demais variáveis, mas de pouca dependência. Todavia, não houve variáveis selecionadas com essa característica (GODET, 2000).

No Q3, estabilizam-se as variáveis com maior grau de dependência, sendo que estas, para gerar um melhor desenvolvimento, necessitam manter uma relação com as variáveis de forte influência, localizadas no quadrante acima, para possibilitar um melhor destaque. A única variável encontrada nesse quadrante foi “preços" (hotel, transporte e alimentação). Essa variável foi classificada na pesquisa como sendo de alto grau de dependência e fraco grau de influência (GODET, 2000).

No Q4, identificam-se as variáveis de baixo grau de dependência e baixo grau de influência, evidentemente desprezadas para a construção dos cenários (GODET, 2000).

\subsection{CENÁRIOS DE 2013 A 2023}

De acordo com Davis (2002), os cenários não precisam ser absolutamente corretos. Simplesmente seus elaboradores precisam ser menos "surpreendidos" do que aqueles que não praticam esse pensamento. Dessa forma, com base no quadro 2, foram traçados dois cenários para o turismo cearense, um realista e outro pessimista:

QUADRO 2 - CENÁRIOS REALISTA E PESSIMISTA

\begin{tabular}{|c|c|}
\hline CENÁRIOS & EVENTOS - VARIÁVEIS-CHAVE \\
\hline \multirow[t]{2}{*}{ Cenário A } & Aumento da quantidade de atrações turísticas \\
\hline & $\begin{array}{l}\text { Aumento da quantidade das rotas e diminuição dos preços das passagens nacionais } \mathrm{e} \\
\text { internacionais }\end{array}$ \\
\hline \multirow{5}{*}{ Realista } & Aumento da quantidade de mix de serviços oferecidos pelas empresas locais \\
\hline & $\begin{array}{l}\text { Aumento da capacitação de mão de obra (profissionais poliglotas, atendimento personalizado, } \\
\text { relacionamento com o cliente) }\end{array}$ \\
\hline & Melhoria no desempenho da economia brasileira \\
\hline & Aumento da divulgação do turismo cearense nas mídias nacionais e internacionais \\
\hline & Melhoria nos preços (hotel, alimentação, transporte, lazer) \\
\hline \multirow{3}{*}{ Cenário B } & Redução da quantidade das atrações turísticas \\
\hline & Redução da quantidade das rotas e aumento dos preços das passagens nacionais e internacionais \\
\hline & Redução do mix de serviços oferecidos pelas empresas locais \\
\hline \multirow[t]{4}{*}{ Pessimista } & $\begin{array}{l}\text { Redução da capacitação de mão de obra (profissionais poliglotas, atendimento personalizado, } \\
\text { relacionamento com o cliente) }\end{array}$ \\
\hline & Piora no desempenho da economia brasileira \\
\hline & Redução da divulgação do turismo cearense nas mídias nacionais e internacionais \\
\hline & Aumento nos preços (hotel, alimentação, transporte, lazer) \\
\hline
\end{tabular}

Fonte: Dados da pesquisa (2013). 


\subsubsection{Cenário A - Realista}

Para os próximos dez anos (2013 - 2023), prospecta-se o aumento da quantidade das atrações turísticas no estado do Ceará, assim como o aumento do mix de serviços oferecidos pelas empresas locais, os quais deverão prezar cada vez mais pela capacitação de mão de obra local, focando principalmente profissionais poliglotas e que proporcionem um atendimento personalizado e de excelência aos clientes. Deverá aumentar também a divulgação do turismo cearense nas mídias nacionais e internacionais, o que poderá ocasionar um aumento da quantidade das rotas nacionais e internacionais com destino ao Estado. Além disso, prospecta-se também melhoria nos preços de hotéis, alimentação, transporte e lazer, e diminuição do preço das passagens nacionais e internacionais. As projeções indicam ainda a melhoria no desempenho da economia brasileira.

\subsubsection{Cenário B - Pessimista}

Para os próximos dez anos (2013 - 2023), prospecta-se uma redução da quantidade das atrações turísticas no Ceará, assim como a diminuição do mix de serviços oferecidos pelas empresas locais, que deverão prezar cada vez menos pela capacitação de mão de obra local. Deverá diminuir também a divulgação do turismo cearense nas mídias nacionais e internacionais, o que poderá ocasionar uma redução da quantidade das rotas nacionais e internacionais com destino ao Estado. Além disso, prevê-se também o aumento nos preços de hotéis, alimentação, transporte e lazer, com aumento do preço das passagens nacionais e internacionais. As prospecções indicam ainda uma piora no desempenho da economia brasileira.

\subsection{ESTRATÉGIAS PARA AMBOS OS CENÁRIOS}

O Estado exerce um papel fundamental no desenvolvimento do turismo de um país, região ou município, seja nas funções de coordenação, planejamento, legislação e regulamentação, incentivo, atuação ou promoção social (UNWTO, 2013). 
Dessa forma, tendo por base os cenários traçados para o turismo cearense referentes ao período de 2013 a 2023, sugerem-se as seguintes estratégias a serem implantadas pelos poderes público e privado para cada um dos cenários:

\subsubsection{Para o cenário A - realista}

A primeira estratégia proposta é a prática de melhores preços e qualidade nos serviços oferecidos para o turista.

Para que o Brasil aproveite o impulso proporcionado pelos eventos esportivos dos próximos anos e se consolide como importante destino turístico mundial, é fundamental que o empresariado se conscientize da importância de cobrar preços justos, pois os valores cobrados pelo setor de turismo, considerados elevados em relação a outros países, ainda preocupam as autoridades brasileiras (AGÊNCIA BRASIL, 2013).

A qualidade da prestação de serviços e produtos oferecidos aos turistas é outra preocupação, pois ela deve ser considerada um fator de sobrevivência das organizações e, para isso, deve ser tratada como um diferencial competitivo, seja em termos de produtos, serviços, métodos de trabalho ou processos produtivos, uma vez que as práticas de qualidade determinam se o turista voltará ou não a um estabelecimento ou região (CARVALHO; PALADINI, 2005).

Outro ponto que deve ser ressaltado como prioridade são as estratégias voltadas para a área da capacitação profissional da comunidade. De acordo com o Ministério do Turismo Brasileiro (2013a), a qualificação dentro de qualquer setor de prestação de serviços é fundamental para que uma empresa ou um órgão público se desenvolva, fortaleça e tenha competitividade, além de aumentar a qualidade dos serviços oferecidos aos turistas de maneira satisfatória. Assim, a segunda política proposta é a de maiores investimentos em cursos e treinamentos oferecidos às comunidades carentes, com o intuito de capacitá-las para serviços turísticos.

De acordo com Castelli (2001), se uma comunidade for bem preparada e conscientizada para o turismo, poderá tirar grandes proveitos, tanto econômicos como culturais, e não será tão dependente do setor público, achando que tudo é dever do Estado, redimindo-se de qualquer responsabilidade. Assim, a terceira estratégia proposta é voltada para a conscientização da sociedade em relação ao direcionamento da 
sustentabilidade, estimulando a valorização e a preservação ambiental e cultural e possibilitando melhorias em infraestrutura básica, fluxo turístico, geração de empregos e aumento da renda familiar. A conscientização é uma ferramenta que possibilita a inclusão comunitária na gestão e na condução do turismo em uma localidade (CASTELLI, 2001).

A quarta proposta é a de incentivos tributários do Governo em busca de novos investidores para o setor turístico cearense. Segundo Castro (2002), a política de incentivos deve construir uma ponte entre o mero mecanismo redutor de custos e preços relativos e as transformações estruturais, o salto qualitativo necessário para a realização do catch up ou "emparelhamento" de uma região atrasada em relação às mais adiantadas. Todavia, o autor ressalta que não se deve avaliar uma política de incentivos somente pelo número de empresas que se conseguiu atrair, mas sobretudo pela qualidade delas, pelas relações interempresariais, intraindustrial e intersetoriais que tais empresas conseguiram promover em uma localidade.

A quinta proposta consiste em continuar buscando estratégias para a utilização da Arena Castelão após os eventos esportivos realizados no Estado e viabilizar espaços como centros de convenções, de cultura e de gastronomia. De acordo com o Governo do Estado do Ceará (2013), no primeiro ano de utilização, após os investimentos e a reinauguração, 45 eventos aconteceram no espaço, entre partidas de futebol, shows nacionais e internacionais, tornando-o um equipamento multiuso e financeiramente sustentável. A promoção de grandes eventos tem sido uma boa estratégia de diversos países para a atração de investimentos e de atenção internacional.

\subsubsection{Para o cenário $\mathrm{B}$ - pessimista}

De acordo com a Revista Turismo e Negócios (2006), a imagem do Brasil no Exterior está estereotipada negativamente pela exploração sexual de crianças e adolescentes e pela forte onda de violência. Dessa forma, a primeira estratégia proposta é a de investimento por meio do poder público para melhorar a qualidade de vida da população através da diminuição da violência, da geração de emprego e renda, da valorização do patrimônio histórico e cultural e do aumento de ações de marketing público, pois, além de melhorar a qualidade de vida da população, isso melhora 
consequentemente a imagem do Brasil no Exterior, para que os turistas se sintam cada vez mais motivados a visitar o País.

A segunda estratégia proposta é a de aumento e diversificação de linhas de financiamentos para empreendimentos turísticos, visando ao fomento e à criação de novas atrações turísticas, além do aumento da quantidade do mix de serviços oferecidos pelas empresas. A atividade turística, tanto no Brasil como em outras partes do mundo, tem um importante relacionamento com o mercado financeiro. A necessidade de recursos para a criação ou a ampliação das suas atividades tem no mercado financeiro um fundamental apoio para as decisões de investimento (VASCONCELOS, 2006).

De acordo com Revista Turismo e Negócios (2006), para o Banco do Brasil, o acesso a créditos em condições diferenciadas viabiliza a modernização e um melhor posicionamento competitivo para as empresas nos mercados interno e externo. Outra vantagem mencionada é a otimização do fluxo de caixa, possibilitando incremento na realização de negócios e proporcionando um maior leque de produtos e serviços de qualidade oferecidos aos turistas (REVISTA TURISMO E NEGÓCIOS, 2006).

A terceira estratégia é o estimulo à criação de parcerias e relacionamentos efetivos entre grupos formais e informais no setor turístico. Essas parcerias têm caráter político e podem contribuir significativamente rumo ao desenvolvimento sustentável, com a criação, por exemplo, de códigos de conduta ou códigos ambientais, sendo possível minimizar impactos negativos em ambientes ameaçados (MTUR, 2013b).

O quarto ponto a ser trabalhado é a criação de estratégias para que se prolongue a estada do turista, fomentando, assim, a economia do País. A World Tourism Organization (UNWTO) aponta que é necessário tornar conhecidas as novas possibilidades de recreação e entretenimento de um local, a fim de que o turista prolongue a sua estada em uma região (UNWTO, 2013). A hospitalidade é outro fator que influencia diretamente na permanência do turista por mais dias. Para ser hospitaleiro, é preciso esmerar-se na excelência dos serviços prestados, educar a comunidade para receber os turistas, investir em infraestrutura básica, porque a hospitalidade está desde o atendimento na compra dos pacotes, passando pelas condições de sinalização, estradas, até a higiene e a segurança dos destinos, podendo ser espontânea ou artificial. Esta última ocorre quando entidades públicas e/ou privadas 
promovem a criação de infraestruturas, forjando uma hospitalidade profissional e muitas vezes para usufruto exclusivo dos turistas (DALPIAZ et al., 2008).

Por fim, as estratégias propostas nos cenários realista e pessimista visam a uma evolução e a uma estruturação do setor turístico cearense que, além de satisfazer o turista, preservem o ambiente e a cultura e objetivam constituir também uma verdadeira alternativa econômica geradora de emprego e renda para a população local.

\section{CONCLUSÃO}

O estudo teve como objetivo buscar responder à indagação de quais estratégias as instituições governamentais e os empresários deveriam considerar para a prospecção do setor turístico cearense nos cenários mais prováveis entre os anos de 2013 e 2023.

Para atingir o objetivo da pesquisa, tomaram-se como base metodológica o modelo de construção de cenários de Godet (2000) e a adaptação realizada por Oliveira e Forte (2009). A utilização do método permitiu a elaboração de dois cenários, um realista e outro pessimista. O primeiro projeta que o mix de serviços oferecidos pelas empresas e o Estado serão ampliados, como também no que se refere à oferta de atrações turísticas no Ceará. Além disso, cada vez mais a capacitação de mão de obra local será valorizada com foco nos profissionais poliglotas, favorecendo um atendimento de qualidade superior. Da mesma forma, haverá uma perspectiva de crescimento na promoção do turismo cearense nas mídias nacionais e internacionais. Os eventos esportivos a ocorrerem entre 2014 e 2016 motivarão a vinda dos turistas ao País e principalmente ao Ceará (CTNF, 2011). No que se refere à prospecção para o preço de hotéis, alimentação, transporte e lazer, como também preço de passagens, nacionais e internacionais, o que se espera é a redução dos preços cobrados pelas empresas cearenses.

Para o cenário pessimista, considera-se que ocorrerá um encolhimento do investimento em atrações turísticas do Estado. Do mesmo modo, isso ocorrerá com o mix dos serviços oferecidos pelas empresas, como também a capacitação da mão de obra local será menos valorizada. O aumento do preço de hotéis, alimentação, transporte, lazer e passagens nacionais e internacionais também é previsto neste cenário, 
implicando uma redução das rotas aéreas nacionais e internacionais para o Estado. Com efeito, a economia projeta um declínio no seu desempenho.

Para os cenários traçados, foram sugeridas estratégias visando ao desenvolvimento, ao crescimento, à conscientização e à sustentabilidade do setor turístico cearense.

Neste trabalho, os autores apresentam como sugestão para outras pesquisas dessa temática uma análise comparativa sobre cenários prospectivos no setor de turismo entre os estados e regiões brasileiras, utilizando-se de maior número de peritos para a elaboração dos cenários e a definição de estratégias públicas e privadas que suportem os cenários prospectados.

No entanto, considera-se relevante esclarecer que o presente trabalho teve como limitação o número de participantes dos respondentes da pesquisa, devido à incompatibilidade de horários, o que poderia ter fornecido uma maior margem de informações para as conclusões.

\section{REFERÊNCIAS}

AGÊNCIA BRASIL. Ministro do Turismo Alerta Empresários Sobre Importância de Cobrar Preços Justos. Disponível em:

$<$ http://agenciabrasil.ebc.com.br/noticia/2013-05-29/ministro-do-turismo-alertaempresarios-sobre-importancia-de-cobrar-precos-justos>. Acesso em: 06/06/2013.

ALVES, S.; VABO JÚNIOR, F. O.; VAZ, L. F. H; SALOMÃO, R. Cenários para a Indústria de Turismo e Viagens - Um Ecossistema em Transformação. In: XXXIII ENCONTRO DA ANPAD, 2009, Anais... Rio de Janeiro, 2009, v. 33, p. 1-16, 1 CD ROM.

BOLETIM DE DESEMPENHO ECONÔMICO DO TURISMO. Ano IX, n. 34 (jan./mar. 2012) / EBAPE/Núcleo de Turismo, Ministério do Turismo. Rio de Janeiro: Fundação Getulio Vargas, 2012.

BRAINSTORMING. Método Grumbach: Brainstorming Assessoria de Planejamento e Informática. 2003. Disponível em:

<http://www.brainstorming.com.br/textos/Metodo.htm>. Acesso em: 15/06/2013.

BUARQUE, S. Metodologia e Técnicas de Construção de Cenários Globais e Regionais. Brasília: IPEA, 2003.

CASTELLI, G. Administração hoteleira. 9. ed. Caxias do Sul: EDUCS, 2001. 
CASTRO, C. A. P. de. Sociologia aplicada ao turismo. São Paulo: Atlas, 2002.

CARVALHO, M. M.; PALADINI, E. P. Gestão da qualidade: teoria e casos. Rio de Janeiro: Campus, 2005.

CEARÁ. Governo do Estado do Ceará. Arena Castelão: Um ano de sucesso. 2013. Disponível em: <http://www.ceara.gov.br/sala-de-imprensa/noticias/9716-arenacastelao-um-ano-de-sucesso>. Acesso em: 16/12/2013.

CERVO, A. L.; BERVIAN, P. A.; SILVA, R. da. Metodologia Científica. 6 ed. São Paulo: Pearson Prentice Hall, 2007.

CLIBBENS, N.; WALTERS, S; BAIRD, W. Delphi research: issues raised by a pilot study. Nurse Researcher, v. 19, n. 2, p. 37-43, 2012.

COSTA, B. K.; FISCHMANN, A. A.; BOAVENTURA, J. M. G.; MUNIZ, C. M. R.; NERY, T. R. Adequação e uso de cenários prospectivos: um estudo no órgão municipal de turismo de Natal. Turismo - Visão e Ação, v. 9, n.1, p. 07-17, jan./abr. 2006.

COSTA, H. A.; NASCIMENTO, E. Cenários para o turismo no Brasil 2007-2010: análise da consistência metodológica e plausibilidade dos cenários. Caderno Virtual de Turismo, v. 7, n. 3, 2007.

CRUZ, R. C. A. da. Planejamento governamental do turismo: convergências e contradições na produção do espaço. In: LEMOS, A. I. G. de; ARROYO, M.; SILVEIRA, M. L. (Orgs.) América Latina: cidade, campo e turismo. São Paulo: Universidade de São Paulo, p. 337-350, 2006.

CTNF - Conselho de Turismo e Negócios da FECOMÉRCIO. Crescimento e projeção do turismo brasileiro. 2011. Disponível em: <http://www.fecomercio.com.br/email/ctn/24.05.2012.html $>$. Acesso em: 27/01/2013.

CUNHA, L. A Definição e o Âmbito do Turismo: um aprofundamento necessário. Lisboa: Recil, 2010.

DAVIS, G. Scenarios as Tool for the 21st Century. In: PROBING THE FUTURE CONFERENCE. England: Shell International Limited, 2002. Disponível em: $<$ https://www.pik-potsdam.de/news/public-events/archiv/alter-net/formerss/2006/programme/31-

08.2006/leemans/literature/davis_how_does_shell_do_scenarios.pdf $>$. Acesso em: 04/07/2013.

DALPIAZ, C. C. R.; DAGOSTINI, A.; GIACOMINI, M. D.; GIUSTINA, D. S. G. M. A Hospitalidade no Turismo: O Bem Receber. 2008. Disponível em: <http://www.serragaucha.com/upload/page_file/hospitalidade-e-bem-receber.pdf>.

Acesso em: 3/6/2013. 
DAY, G. S.; SCHOEMAKER, P. J. Scanning the periphery. Harvard Business Review, v. 1, n., p. 135-149, 2005.

FIFA. Fédération Internationale de Football Association. Partidas. Disponível em: <http://pt.fifa.com/worldcup/destination/cities/city=11693/poster.html>. Acesso em: 20/03/2014.

Estádios. Disponível:

<http://pt.fifa.com/worldcup/destination/stadiums/stadium=5025114/index.html .

Acesso em: 20/03/2014b.

FLICK, U. Uma introdução à Pesquisa Qualitativa. 2. ed. Porto Alegre: Bookman, 2004.

GODET, M. The art of scenarios and strategic planning: tools and pitfalls. Technological Forecasting and Social Change, v. 65, n. 1, 2000.

Manual de Prospectiva Estratégica. Lisboa: Publicações Dom Quixote, 2003.

GÖSSLING, S.; SCOTT, D. Scenario planning for sustainable tourism: an introduction. Journal of Sustainable Tourism, v. 20, n. 6, p. 773-778, 2012.

HEIDJEN, K. van D. Planejamento por Cenários: a arte da conversação estratégica. Porto Alegre: Bookman, 2009.

HUNT, L. M.; BOXALL, P.; ENGLIN, J.; HAIDER, W. Forest harvesting, resourcebased tourism, and remoteness: an analysis of northern Ontario's sport fishing tourism. NRC Research Press, s. 35, p. 401-409, mar. 2005.

LINSTONE, H. A.; TUROFF, M. The Delphi Method: techniques and applications. Newark: New Jersey Institute of Technology. 2002. Disponível em: <www.is.njit.edu/pubs/delphibook>. Acesso em: Jan. 2013.

MARCIAL, ELAINE; COSTA, ALFREDO. E. Competitive intelligence versus spying: building a vision of the future. In: Anais do BALAS 2002 - Business Association of Latin América, Tampa, Mar. 2002

MARCIAL, E. C.; GRUMBACH, R. J. S. dos. Cenários Prospectivos: como construir um futuro melhor. Rio de Janeiro: FGV, 2002.

MALHOTRA, N. K. Pesquisa de Marketing: uma orientação aplicada. 4 ed. Porto Alegre: Bookman, 2006.

MTUR. MINISTÉRIO DO TURISMO. Dados e Fatos. Disponível em: $<$ http://www.dadosefatos.turismo.gov.br/dadosefatos/home.html>. Acesso em: 24/02/2013a. 
Boletim de Desempenho Econômico do Turismo 2013. Disponível em: $<\mathrm{http}$ ://www.dadosefatos.turismo.gov.br/export/sites/default/dadosefatos/conjuntura_ec onomica/boletim_desempenho_turismo/download_boletim_desempenho_economico_tu rismo/BDET_-_37.pdf>. Acesso em: 24/02/2013b.

\section{- Estatísticas Básicas do Turismo \\ 2012. Disponível em:} <http://www.turismo.gov.br>. Acesso em: 21/01/2013c.

Copa: MTur regionaliza gastos de turistas por cidade-sede. Disponível em: <http://www.turismo.gov.br/turismo/noticias/todas_noticias/20140514_3.html>. Acesso em: 20/03/2014.

MORIARTY, J. Theorising scenario analysis to improve future perspective planning in tourism. Journal of Sustainable Tourism, v. 20, n. 6, p. 779-800, jul. 2012.

OLIVEIRA, O. V.; FORTE, S. H. A. C. A indústria bancária brasileira: Construindo cenários prospectivos e identificando as estratégias de utilização mais provável. Revista Portuguesa e Brasileira de Gestão, v. 8, p. 64-76, 2009.

PORTER, M. E. Vantagem competitiva: criando e sustentando um desempenho superior. Rio de Janeiro: Campus, 1990.

PORTUGUEZ, A. P. Agroturismo e desenvolvimento regional. São Paulo: Hucitec, 2002.

REVISTA TURISMO E NEGÓCIOS. Banco do Brasil oferta crédito ao setor turístico. 2006. Disponível em:

$<$ http://www.revistaturismoenegocios.com/materia.php?c=399>. Acesso em: 02/06/2013.

SETUR - Secretaria de Turismo do Ceará. Indicadores Turísticos 1995/2011. Disponível em:

<http://www.setur.ce.gov.br/categoria1/estudos-e-pesquisas/Indicadores\%202012.pdf>. Acesso em: 21/01/2013.

SOBREIRA, M. C.; MACHADO, C. O.; REBOUCAS, C. Q.; FORTE, S. H. A. C.; ALMEIDA, S. R.; OLIVEIRA, O. V. Cenários Prospectivos no Combate ao Turismo Sexual Internacional em Fortaleza. IN: XXXVII ENCONTRO DA ANPAD, 2013. Anais... Rio de Janeiro. XXXVII EnANPAD, Rio de Janeiro: 2013. v. 37. p. 1-16, 1 CD Rom.

SHUIFA, K.; CHENGUANG, P.; JIAHUA, P.; YAN, Z.; YING, Z. Multiplier effect of the development of forest park tourism on employment creation in China. Journal of Employment Counseling, v. 48, p. 136-144, sep. 2011.

THOMPSON, M. Considering the implication of variations within Delphi research. Family Practice, v. 26, n. 5, p. 420-424, 2009. 
TOMAZZONI, E. L. Turismo e desenvolvimento regional: Modelo APL Tur aplicado à Região das Hortênsias. Tese (Doutorado em Ciências da Comunicação). Universidade de São Paulo, São Paulo, 2007.

UNWTO - World Tourism Organization. World Tourism Barometer. Madri, v. 7, n. 21. Disponível em: 〈http://www.unwto.org>. Acesso em: 16/01/2013.

VALENÇA, S.; SOBRAL, M. do C. M; RAMOS, D.; CAVALCANTI, C. Prospective scenarios of the environmental management of the tourist destination of Porto de Galinhas based on the enlargement of the industrial and portuary complex of Suape, Pernambuco, Management of Environmental Quality: An International Journal, v. 21 (3), p. 336-350, 2010.

VASCONCELOS, M. A. S. Introdução à economia do turismo. São Paulo: Saraiva, 2006.

WTTC - World Travel \& Tourism Council. Travel \& Tourism: Economic Impact 2012 World. Disponível em:

<http://www.wttc.org/site_media/uploads/downloads/world2012.pdf $>$. Acesso em: $18 / 12 / 2012$.

Recebido em: 17-10-2013.

Aprovado em: 16-11-2013. 